\title{
Trata de PERSONAS Más ALLÁ de LA EXPLOTACIÓN SEXUAL EN COLOMBIA: HACIENDO VISIBLE AL ESCLAVO EN CASA
}

Alejandro Cáceres Monroy ${ }^{(a)}$

BEYOND SEXUAL EXPLOITATION IN HUMAN TRAFFICKING

IN COLOMBIA: MAKING THE SLAVE AT HOME VISIBLE

TRÁFICO DE PESSOAS MAIS ALÉM DA EXPLORAÇÃO SEXUAL

NA COLÔMBIA: TORNANDO VISÍVEL O ESCRAVO EM CASA

Fecha de recepción: 19 de enero del 2018

Fecha de aprobación: 8 de mayo del 2018

Disponible en línea: 20 de junio del 2018

Sugerencia de citación:

Cáceres Monroy, A. (2018). Trata de personas más allá de la explotación sexual en Colombia: Haciendo visible al esclavo en casa. Razón Crítica, 5, 139-175, doi: http://dx.doi.org/10.21789/25007807.1279

(a) Abogado y Politólogo de la Universidad de los Andes (Colombia), con Maestría en Derecho Internacional y Comparado de la Universidad de California, Los Ángeles, y Estudios de Género y Sexualidad en la Universidad de Miami

Oficial nacional para la reducción de pobreza en el Programa de Naciones Unidas para el Desarrollo PNuD, Colombia https:/ / orcid.org/0000-0002-9625-3904

acaceresmonroy@gmail.com 


\section{R E S U M E N}

La trata de personas es un fenómeno complejo que se beneficia de relaciones desiguales de poder y obstruye el ejercicio de los derechos de sus víctimas. Este artículo ofrece una explicación de la manera en la que el fenómeno ha sido abordado legalmente, particularmente desde su concepción penal. A partir de una mirada histórica del tipo penal, incluyendo el influjo del derecho internacional, en conjunto con las modificaciones legales y sus interpretaciones jurisprudenciales, se pretende explicar que la calificación del delito y su posterior acción de enjuiciamiento dependen excesivamente de interpretaciones de los fiscales. Adicionalmente, las ventajas que la comunidad internacional y las organizaciones de víctimas de trata han reconocido a la complejidad del tipo penal colombiano se han convertido en un obstáculo para su efectiva judicialización y procesamiento. Tales obstáculos se hacen incluso más evidentes cuando se habla de trata de personas con fines distintos a la explotación sexual, particularmente la trata de personas alrededor de la explotación laboral y las relaciones de servidumbre y esclavitud a las que son sometidas algunas trabajadoras domésticas. De esta manera, los retos alrededor de una persecución efectiva de las personas involucradas en la trata de personas deben partir del reconocimiento de tales dificultades interpretativas y culturales que hacen que la norma, tal como está, no sea del todo eficiente para combatir el fenómeno.

PALABRAS CLAVE: explotación laboral, explotación sexual, persecución penal, trabajadores domésticos, trata de personas 


\section{A B S T R A C T}

Human trafficking is a complex phenomenon that benefits from unequal power relations and impedes the exercise of victims' rights. This article aims to explain how such phenomenon has been approached from the legal perspective; in particular its criminal conception. From a historical point of view of criminal law that embraces the influence of international law, in conjunction with legal amendments and its corresponding interpretations, this work is intended to explain that this type of criminal offense and its subsequent prosecution are excessively dependent on the prosecutors' interpretations. Moreover, the advantages that both the international community and victims' organizations have recognized in the complexity of the Colombian criminal system have become more of a burden for an effective prosecution. These problematic situations become more evident when referring to human trafficking for purposes other than sexual exploitation, particularly around labor exploitation and the servitude and slavery relationships to which some domestic workers are subjected. In this way, the challenges surrounding the effective prosecution of human trafficking situations must recognize the interpretative and cultural difficulties that make current regulations not fully efficient for battling this phenomenon.

KEY WORDS: Human trafficking, sexual exploitation, labor exploitation, domestic workers, criminal prosecution

\section{R E S U M O}

O tráfico de pessoas é um fenômeno complexo que se beneficia de relações desiguais de poder e obstrui o exercício dos direitos de suas vítimas. Este artigo pretende dar uma explicação sobre a maneira na qual o fenômeno é abordado legalmente, em particular a partir de seu conceito penal. Sob uma visão histórica do tipo penal, que inclui o influxo do direito internacional em conjunto com as modificações legais e suas interpretações jurisprudenciais, pretende explicar que o delito e sua posterior ação do procedimento dependem excessivamente de interpretações dos fiscais. Além disso, as vantagens que a comunidade internacional e as organizações de vítimas de tráfico têm reconhecido à complexidade do tipo penal colombiano têm se tornado um obstáculo para sua efetiva judicialização e processamento. Tais dificuldades fazem-se inclusive mais evidentes quando se fala de tráfico de pessoas com fins diferentes ao da exploração sexual, particularmente ao redor da exploração do seu trabalho e das relações de escravidão às quais são submetidas algumas trabalhadoras domésticas. Dessa forma, os desafios em torno de uma persecução efetiva das situações de tráfico de pessoas devem reconhecer essas dificuldades interpretativas e culturais que fazem com que a normal tal como está não seja de todo eficiente para combater o fenômeno.

PALAVRAS-CHAVE: exploração do trabalho, exploração sexual, persecução penal, trabalhadores domésticos, tráfico de pessoas. 
En los últimos diez años, el número de turistas en Colombia ha ido en aumento (World Travel y Tourism Council, 2017). Esto se debe a múltiples razones, entre las que se cuentan la pacificación de territorios, el mejoramiento en las condiciones de seguridad, un crecimiento económico más o menos sostenido, así como agresivas campañas publicitarias de parte de las agencias nacionales responsables del tema. Estas campañas ${ }^{1}$ invitan a explorar cultura y naturaleza, comida, deportes y aventuras.

Las campañas son de vieja data y, particularmente, la agencia estatal de turismo del gobierno anterior identificó a las mujeres colombianas como uno de los espacios a ser explorados, promoviéndolas como uno de los recursos que los turistas podían disfrutar cuando visitaban el país. "Countless beautiful women and orchids" [un sinnúmero de mujeres y orquídeas hermosas] dice el video promocional en inglés que se usó para invitar turistas ${ }^{2}$. Colombia es Pasión fue la marca país desarrollada bajo el gobierno Uribe (2002-2010), y su logotipo simulaba un corazón y la silueta de una mujer (Presidencia de la República, s.f.). En este contexto, en palabras de Catalina Ruíz-Navarro (11 de septiembre del 2013), se "vende a Colombia como tierra de 'lindas mujeres', como si eso fuera un atractivo turístico, como si fuéramos un recurso natural, un incentivo para la inversión extranjera que muy probablemente ve en la explotación sexual otra apetitosa locomotora [de desarrollo]". Este tipo de campañas está alimentado por la difundida creencia de que Colombia es un país con mujeres hermosas. Varios concursos de belleza, rankings y medios de comunicación globales

Véase Procolombia (s.f.)

2 Véase el video Colombia is Passion (Rafael Suarez Buelvas, 4 de febrero del 2008). 
contribuyen a difundir la idea de que las mujeres colombianas son particularmente hermosas ${ }^{3}$.

Esta narrativa no solo ha favorecido un aumento del turismo -mucho de este, sexual ${ }^{4}$, sino que también ha generado debates académicos y judiciales alrededor de la trata de personas, pues es el turismo sexual y la trata con fines de explotación sexual lo que parecería primar en un país con este tipo de "recursos explotables". El turismo sexual ${ }^{5}$ en Colombia es rampante ${ }^{6}$. Como lo indica el Departamento de Estado en su informe "Trata de Personas del 2014" (U.S. Department of State, s.f.), Colombia es el país de origen de hombres, mujeres y niños víctimas de la trata sexual. Una gran parte del tráfico sexual de mujeres y niños colombianos se produce al interior el país. Las autoridades estadounidenses, por ejemplo, reportaron altos índices de prostitución infantil en las zonas de turismo y alrededor de grandes industrias extractivas.

Los ojos de la comunidad internacional, el gobierno y la sociedad civil han estado enfocándose en el tema de la trata de personas con fines de explotación sexual en el país. Sin embargo, las víctimas de trata no son las únicas víctimas de este delito, pues las mujeres colombianas han enfrentado por muchos años otros tipos de explotación no menos perversos, pero, eso sí, ampliamente aceptados.

Este texto se divide en tres partes. Primero, se hace un resumen de la historia del delito de trata de personas en Colombia y se muestra de qué manera la comprensión por parte de los fiscales y jueces ha afectado el poder transformador de la disposición legal (Pound, 1927). En segundo lugar, se intentará problematizar la idea de la trata sexual como el único tipo de trata que sucede en el país;

$3 \quad$ Véase por ejemplo Moreno (13 de mayo del 2013) y Daily Mail Reporter (13 de mayo del 2013).

4 Véase por ejemplo, Editorial (13 de noviembre del 2017).

5 De acuerdo con la Organización Mundial del Turismo, en su Asamblea General Onceava Sesión - El Cairo (Egipto), 17-22 octubre de 1995 (Resolución a/res/338 (xi), el turismo sexual se puede definir como "viajes organizados desde dentro del sector del turismo, o de fuera de este sector, pero utilizando sus estructuras y redes, con el objetivo principal de llevar a cabo una relación sexual comercial por el turista con los residentes en el destino".

$6 \quad$ Una vez más los rankings de Internet identifican a Colombia como el quinto destino de turismo sexual: "en la calle muchas trabajadoras sexuales colombianas bajan sus precios si el cliente es atractivo y un buen negociador, puede ser por qué el país es tan popular cuando se trata del turismo sexual. Sin embargo, probablemente, también acuden a Colombia con la esperanza de que cada mujer se verá con curvas, como la colombiana Sofía Vergara" (Burns, 21 de junio, s.a.; traducción propia). 
esta sección se referirá a los datos oficiales y algunas decisiones de la justicia colombiana. En tercer lugar, se expondrá la aceptación cultural de la trata de personas como uno de los principales problemas con respecto a la vigencia del delito. Por último, se dará una conclusión que aboga por una comprensión holística de la trata de personas, que sirva a más personas y que al mismo tiempo permita respetar su agencia.

\section{Complejidades de la trata de personas, la explotación sexual y el enjuiciamiento}

En Colombia, la prostitución no es un delito ni se encuentra regulada. Esto ha creado una comprensión problemática en torno al comercio sexual y, por lo tanto, una manera ineficaz de luchar contra la trata de personas en cualquiera de sus estados. Fue solo con la adquisición de compromisos internacionales que se obligó a Colombia a cambiar su enfoque sobre la trata de personas, modificando la comprensión del delito. Esta modificación impactó a todo el sistema judicial. Aquí un resumen de tales cambios.

En la Ley 599 del 2000, que crea el Código Penal, la trata de personas era parte del título IV (Delitos contra la libertad, integridad y formación sexual), y era parte del capítulo IV (Proxenetismo), en los siguientes términos:

Artículo 215. Proxenetismo. Quien promueva, induzca, constriña o facilite la entrada o salida de una persona para practicar la prostitución será sancionado con prisión de cuatro (4) a seis (6) años y multa de setenta y cinco (75) a setecientos cincuenta (750) salarios mensuales mínimos.

Esta definición del proxenetismo era extremadamente limitada, y en lugar de trabajar contra la trata de personas era una prohibición de facto de la prostitución, pues definía como ilegal el promover, inducir o facilitar la práctica de la prostitución o el comercio de una persona; es decir, la única práctica legal de sexo comercial era aquella que se realizaba sin intermediarios. Esta definición era limitada, además, porque definía la trata de personas solamente en términos de fines de prostitución. Así pues, cualquier 
otra explotación era legal o era tramitada como un delito diferente: como lesiones personales (extracción de órganos) o constreñimiento ilegal (trabajos forzados, matrimonio servil), entre otros.

Desde el 2004 Colombia es parte del Protocolo para prevenir, reprimir y sancionar la trata de personas, especialmente la de mujeres y niños, que complementa la Convención de las Naciones Unidas contra la Delincuencia Organizada Transnacional ("Protocolo de Palermo") 7. Sin embargo, el gobierno colombiano impulsó la creación de una legislación nacional para ajustar la ley con el Protocolo de Palermo antes de la ratificación formal del mismo. Así, la Ley 747 del 2002 hizo algunas enmiendas y adiciones al Código Penal (Ley 599 del 2000), y modificó el delito de trata de personas. Al tiempo, la Ley 747 creó el delito de tráfico de migrantes, derogó el artículo 215 de la Ley 599 del 2000, y definió un nuevo delito de trata de personas, que quedó puesto en el capítulo v (Delitos contra la autonomía personal) del título III (Delitos contra la libertad individual y otras garantías) de la Ley 599 del 2000 mediante la adición del artículo 188-A, redactado de la siguiente manera:

Artículo 188-A. La trata de personas. El que promueva, facilite, induzca, constriña, financie, colabore o participe en el traslado de una persona dentro del país o en el extranjero utilizando cualquier forma de violencia, amenazas of fraude, con fines de explotación, a ejercer la prostitución, la pornografía, la servidumbre por deudas, la mendicidad, el trabajo forzado, el matrimonio servil, la esclavitud con el propósito de obtener beneficio económico u otro beneficio, para sí mismo o para otra persona será sancionado con prisión de diez (10) a quince (15) años y multa de seiscientos (600) a mil (1.000) salarios mínimos legales mensuales en el momento de la condena.

Artículo 188-B. Circunstancias agravantes. Las sanciones por los delitos enunciados en el artículo 188 y 188-A, se incrementarán en un tercio a la mitad cuando:

7 Firmado en 12/02/00 y ratificado en 08/04/04. Se trata de un protocolo de la Convención contra la Delincuencia Organizada Transnacional. Este es el principal instrumento internacional en la lucha contra la delincuencia organizada transnacional. 
I. Cuando se realice en persona que padezca, inmadurez psicológica, trastorno mental, enajenación mental y trastorno psíquico, temporal o permanentemente o sea menor de 18 años. (Énfasis añadido)

Es importante notar que este delito no sigue la definición plasmada en el artículo 3 del Protocolo de Palermo (Asamblea General de las Naciones Unidas, 2000), a saber:

(A) Por "trata de personas" se entenderá la captación, el transporte, el traslado, la acogida o la recepción de personas, recurriendo a la amenaza o al uso de la fuerza u otras formas de coacción, al rapto, al engaño, al abuso de poder o de una situación de vulnerabilidad o a la concesión o recepción de pagos o beneficios para obtener el consentimiento de una persona que tenga autoridad sobre otra, con fines de explotación. Esa explotación incluirá, como mínimo, la explotación de la prostitución ajena u otras formas de explotación sexual, los trabajos o servicios forzados, la esclavitud o las prácticas análogas a la esclavitud, la servidumbre o la extracción de órganos;

(B) El consentimiento dado por la víctima de la trata de personas a toda forma de explotación que se tenga la intención de realizar descrita en el apartado (a) del presente artículo no se tendrá en cuenta cuando se haya recurrido a cualquiera de los medios enunciados en dicho apartado.

Así las cosas, existen tres aspectos clave que la Ley 747 del 2002 excluye respecto al Protocolo de Palermo. En primer lugar, la acción es restrictiva a la transferencia de la persona, es decir, no contempla la acogida, la recepción, el transporte y el reclutamiento. En segundo lugar, los medios siguen siendo rudimentarios y no incluyen el abuso de poder o el abuso de una situación de vulnerabilidad. Por último, el consentimiento de la víctima parecería resolver el ilícito.

Luego de un año de vigencia de esta norma, el Congreso colombiano aprobó la Ley 800 del 2003, que ratificó el Protocolo de Palermo. Al año siguiente, el gobierno impulsó una modificación general del Código Penal, con la cual se aumentaron las penas para todos los delitos, mediante la Ley 890 del 2004. 
Cinco años después de la firma del Protocolo de Palermo se promulgó el marco para su aplicación mediante la Ley 985 del 2005, que se aprobó con el propósito de crear "medidas contra la trata de personas y adoptar normas para la atención y protección de las víctimas de la misma”. El Artículo 1 de la Ley 985 establece que deberá interpretarse en consonancia con la Ley 800 del 2003, es decir el Protocolo de Palermo ${ }^{8}$. El artículo 3 de la Ley 985 establece que el artículo 188-A de la Ley 599 del 2000, complementada por la Ley 747 del 2002 y modificada por la Ley 890 del 2004, quedará así:

Artículo 188-A. Trata de personas. El que capte, traslade, acoja o reciba a una persona, dentro del territorio nacional o hacia el exterior, con fines de explotación, incurrirá en prisión de trece (13) a veintitrés (23) años y una multa de ochocientos (800) a mil quinientos (1.500) salarios mínimos legales mensuales vigentes.

Para efectos de este artículo se entenderá por explotación el obtener provecho económico o cualquier otro beneficio para sí o para otra persona, mediante la explotación de la prostitución ajena u otras formas de explotación sexual, los trabajos o servicios forzados, la esclavitud o las prácticas análogas a la esclavitud, la servidumbre, la explotación de la mendicidad ajena, el matrimonio servil, la extracción de órganos, el turismo sexual u otras formas de explotación.

El consentimiento dado por la víctima a cualquier forma de explotación definida en este artículo no constituirá causal de exoneración de la responsabilidad penal. (Énfasis añadido)

Las principales modificaciones se introdujeron para ajustar la mayoría de los problemas de la Ley 747 del 2002 en relación con el Protocolo de Palermo. Para comprender la modificación es necesario resaltar cuarto cosas. Primero, las acciones del tipo ahora incluyen el traslado, la acogida o el recibimiento; el reclutamiento

8 De acuerdo con la Convención de Viena sobre el Derecho de los Tratados, en su Artículo 9, la adopción del texto de un tratado se efectuará por consentimiento de los Estados participantes. Por lo tanto, una ley que ratifique los tratados internacionales no puede añadir o suprimir cualquier parte del tratado, a menos que el Estado haya hecho una reserva. En este caso en particular, Colombia no realizó reserva alguna. 
no se encuentra, pero se puede entender como la captación. En segundo lugar, los medios se eliminan en el delito colombiano, lo que significa que las víctimas no tienen que ser amenazadas, coaccionadas, secuestradas, entre otras, a fin de ser consideradas como víctimas de trata ${ }^{9}$. En tercer lugar, la Ley 985 modifica la palabra prostitución y pornografía, e introduce el concepto de explotación sexual. Al mismo tiempo, incluye prácticas análogas a la esclavitud, al turismo sexual y a la extracción de órganos. Es importante tener en cuenta que desde el 2002 el delito colombiano incluye la mendicidad, aunque esta no forma parte de los objetivos del Protocolo de Palermo. Finalmente, el consentimiento de la víctima no es una forma de exclusión de la responsabilidad penal. Actualmente, esta es la definición del delito en Colombia.

Lo anterior evidencia una amplia influencia del Protocolo de Palermo en el delito de trata de personas en Colombia. La definición de Colombia es de alguna manera mejor para las víctimas: excluye los medios, añade más fines de trata y, como en el Protocolo de Palermo, el consentimiento de la víctima es irrelevante. Sin embargo, la evolución histórica del delito ha tenido impactos en la forma en que se lo procesa. El cambio del proxenetismo a la trata de personas, así como que esta contemple otros fines adicionales a la explotación sexual, no es fácil de entender para algunos actores del sistema judicial. De manera similar, el cambio del interés jurídico protegido, que pasa de la libertad sexual, en el 2000, a la libertad individual, en el 2005, constituyó una revolución completa de la conducta castigada penalmente, revolución que no necesariamente tuvo efectos en la persecución de la conducta.

Este cambio, dado en menos de cinco años e impulsado en parte por la comunidad internacional, no se ha traducido

9 Los "medios" se refieren a la gama de formas en las que una persona coacciona o controla a otra persona. Sin embargo, estos "medios", según el Protocolo de Palermo, no se aplicarán cuando la víctima sea menor de edad (menor de 18 años). En los "trabajos preparatorios" del Protocolo, en la novena sesión del Comité Especial, la decisión de la eliminación de los "medios" se convirtió en un requisito para menores de edad, a pesar de que negociar el resto del artículo les tomó tres sesiones más. Esta protección específica para los niños se basa en la presunción legal de que los menores no tienen agencia. Sin embargo, en la legislación colombiana, ni los menores ni los mayores de edad tienen agencia, y los "medios" para controlar o coaccionar a otra persona están ausentes. Esta discusión excede el propósito de este trabajo, pero es importante señalar lo problemático que esto podría ser cuando se es reclutado voluntariamente para realizar un trabajo en el extranjero, cuando se decide libremente convertirse en una prostituta o vender sus propios órganos. Véase Montoya (2012). 
necesariamente en una mejor persecución de la trata de personas. Como señaló uno de los fiscales asignados a los casos de trata de personas en una entrevista del 2010 (Abadía, 2012), según el artículo 188-A, la explotación es requisito para poder hablar del delito de trata de personas. Sin embargo, los jueces, "con la simple evidencia de un caso relacionado con comercio sexual, insisten en mantener el juicio como un caso de la trata de personas, incluso en los casos en que la explotación no está clara”. Para la Fiscalía se trata de un error de tipo, porque la libertad individual no se viola si alguien práctica la prostitución con lucro. Por lo tanto, la falta de un "beneficio económico o cualquier otro beneficio para sí o para otra persona, a través de la explotación" desdibuja el delito porque ni la autonomía ni la libertad individual son violadas, pues se olvida la importancia del "a través de".

Con este relato se evidencia que la interpretación de fiscales y jueces podría ser errada. Por un lado, el fiscal olvida que el delito excluye el consentimiento de la víctima, lo que significa que incluso si la/el prostituta/o está de acuerdo con su comercialización, la conducta del intermediario siempre será ilegal. Sin embargo, esto no es simple, por ejemplo, en un caso en el que una prostituta libre puede no ser sujeto de alguna acción penal en virtud de la infracción debido a que no fue acogida, trasladada, recibida o capturada. La diferencia entre el Protocolo de Palermo y el artículo 188-A sobre reclutamiento es relevante porque la palabra reclutamiento reconoce cierto nivel de agencia por parte del actor, mientras que la captura no ${ }^{10}$. Por otra parte, la interpretación de los jueces se mantiene bajo una comprensión del delito de proxenetismo que no reconoce que el delito no es contra la libertad sexual, sino contra la autonomía y la libertad. Bajo tal interpretación la prostitución es siempre ilegal y las personas involucradas en el comercio sexual, incluidas las prostitutas ${ }^{11}$, serán siempre sancionadas.

10 Según Carr, Milgram, Kim y Warnath (2014, p. 132), el reclutador "ofrece unas promesas falsas para atrapar a una víctima específica en un esquema de la trata; [...] quien aparentemente hace representaciones acerca de la naturaleza de la obra y/o cargos u honorarios exorbitantes que conducen a la servidumbre por deudas [...]". 11 Amplía literatura se ha escrito sobre los peligros para la vida y seguridad de las mujeres cuando se criminaliza la prostitución. Véase por ejemplo, Lucas (1995), O’Neill (2001), Bromberg, 1997, Landau (8 de abril del 2008), Anderson (2002). 
Esta interpretación se hace aún más compleja cuando el artículo 188-A se lee en conjunto con otras disposiciones en el Código Penal colombiano, tales como:

Artículo 213. Inducción a la prostitución. El que con ánimo de lucrarse o para satisfacer los deseos de otro, induzca al comercio carnal o a la prostitución a otra persona, incurrirá en prisión de dos (2) a cuatro (4) años y multa de cincuenta (50) a quinientos (500) salarios mínimos legales mensuales vigentes.

Artículo 213-A. Proxenetismo con menor de edad. El que con ánimo de lucro para sí o para un tercero o para satisfacer los deseos sexuales de otro, organice, facilite o participe de cualquier forma en el comercio carnal o la explotación sexual de otra persona menor de 18 años, incurrirá en prisión de catorce (14) a veinticinco (25) años y multa de sesenta y siete (67) a setecientos cincuenta (750) salarios mínimos legales mensuales vigentes.

Artículo 214. Constreñimiento a la prostitución. El que con ánimo de lucrarse o para satisfacer los deseos de otro, constriña a cualquier persona al comercio carnal o a la prostitución, incurrirá en prisión de cinco (5) a nueve (9) años y multa de cincuenta (50) a quinientos (500) salarios mínimos legales mensuales vigentes.

Artículo 217. Estímulo a la prostitución de menores. Modificado por el art. 11, ley 1236 del 2008. El que destine, arriende, mantenga, administre o financie casa o establecimiento para la práctica de actos sexuales en que participen menores de edad, incurrirá en prisión de seis (6) a ocho (8) años y multa de cincuenta (50) a quinientos (500) salarios mínimos legales mensuales vigentes.

Artículo 217-A. Demanda de explotación sexual comercial de persona menor de 18 años de edad. El que directamente o a través de tercera persona, solicite o demande realizar acceso carnal o actos sexuales con persona menor de 18 años, mediante pago o promesa de pago en dinero, especie o retribución de cualquier naturaleza, incurrirá por este sólo hecho, en pena de prisión de catorce (14) a veinticinco (25) años. 
Artículo 219. Turismo sexual. El que dirija, organice o promueva actividades turísticas que incluyan la utilización sexual de menores de edad incurrirá en prisión de cuatro (4) a ocho (8) años. La pena se aumentará en la mitad cuando la conducta se realizare con menor de doce (12) años.

Estos delitos, que son parte del título iv (contra la libertad, integridad y formación sexual), forman parte del capítulo IV (explotación sexual) ${ }^{12}$, y están estrechamente relacionados con la modalidad de explotación sexual en el artículo 188-A. Esto ocurre como consecuencia de una falta de técnica legislativa. Ciertas penas son menos severas en algunos de estos delitos, como lo establecen los artículos 214 (prostitución forzada) y 217 (fomento de la prostitución), que dan entre 9 y 14 años de prisión; mientras que la pena de la trata de personas es entre 13 y 23 años. De esta manera, existe la posibilidad de que la superposición de medidas sancionatorias alrededor del comercio sexual pueda debilitar el tipo penal de trata de personas, pues, por un lado, podría ser menos utilizado debido a la enorme cantidad de evidencia que se necesita para demostrar la finalidad de explotación, o debido al excesivo trabajo que supone desarticular una red de trata de personas, mientras que, en contraste, el proxenetismo es dirigido al intermediario y la inducción a la prostitución se refiere a la vulneración de la voluntad. Por otro lado, al existir tantos delitos relacionados con el comercio sexual, y con la obligación de que la imputación debe guardar estrecha relación con la actuación criminal, se dificulta la labor de los fiscales, restándole poder disuasivo $^{13}$ al tipo de trata, pues no es lo mismo ser condenado por proxenetismo que por trata de personas. A esto debe sumársele la amplía posibilidad del desarrollo de una estrategia de defensa que invoque el principio de favorabilidad penal que nuestro ordenamiento constitucional consagra ${ }^{14}$.

12 La Ley 742 cambia el capítulo del título de "proxenetismo" a "explotación sexual". Hoy en día, en Colombia el proxenetismo solo es un delito si la víctima es menor 18 años. 13 Según Von Hirsh (1993, p. 115) "la principal justificación de la pena es la censura: es decir, para transmitir culpa o reprobación a los que han cometido un acto ilícito".

14 Véase Corte Constitucional de Colombia 2011. 
La superposición de medidas penales es problemática debido a que las acciones (captación, transporte, traslado, acogida o recepción de personas) contempladas en el delito de trata de personas, tal como lo señalan Carr et al. (2014, p. 132),

se concibieron para ser amplias abarcando cualquier persona que actúe con la intención ligada con el fin de la esclavitud, la servidumbre, u otras formas de explotación que implican el control sobre otro ser humano que lleva a quien lo comete a ser culpable por el delito de trata de personas.

Así pues, si tales acciones se encuentran dispersas en diferentes tipos en el Código Penal, la trata de personas se convierte en una categoría de delito menos útil y práctica judicialmente.

Lo anterior no es una simple percepción. Debido al lenguaje del Código Penal, según una investigación del 2009 publicada por la Oficina de Naciones Unidas Contra la Droga y el Delito (UNODC), hay una tendencia a criminalizar la conducta de trata en otros delitos:

... la inmensa mayoría de los expertos entrevistados (fiscales, jueces, individuales o colegiados, etc...), afirman que el problema no radica en la redacción de los artículos 188-A y 188-B de la Ley 599 del 2000. [El problema] es que el delito de la trata de personas resulta muy complejo ya que abre el abanico de otras modalidades de trata distintas a la que se usa con fines sexuales o laborales, que pueden catalogarse como las "tradicionales", además por la inclusión de varios verbos rectores que inciden en una aprehensión difícil del fenómeno en cuanto a la correcta tipificación [...]

Luego entonces surge un segundo problema, más allá del sorprendente pero real desconocimiento de la norma por parte de algunos servidores y servidoras en algunas regiones del país -lo cual ya de por sí es un grave indicador-, y es el hecho de aplicar para el juicio de adecuación típica otra conducta punible distinta a la trata, cuando en realidad, y de conformidad con los aspectos fácticos, jurídicos y probatorios se indica que se debe judicializar por este último punible. Esto quiere decir que la complejidad de la estructura del delito de trata causa 
confusión típica (Londoño, Luna de Aliaga, Mateus, Varón y Vanegas, p. 30).

De esta manera, las condiciones, la tendencia a utilizar otros delitos y el desconocimiento de la infracción penal son un terreno fértil para una persecución penal ineficiente que conlleva a tasas significativas de impunidad.

Por último, a pesar de que la legislación penaliza el comercio sexual forzado y la explotación sexual, con un énfasis específico en la protección de menores, la Corte Constitucional de Colombia (en adelante "la Corte") ha ampliado las dificultades en este ámbito.

Según el derecho constitucional colombiano, la Corte es el más alto tribunal y sus decisiones constituyen precedente (erga omnes) al determinar la constitucionalidad de las leyes. En Colombia cualquier persona puede impugnar la constitucionalidad de cualquier Ley creada por el Congreso, incluso cuando el Estatuto no le afecta directamente, a través de una "acción de inconstitucionalidad".

En el 2009, el artículo 213 del Código Penal (Promoción de la prostitución) fue demandado a través de una acción de inconstitucionalidad porque el demandante consideraba que tal artículo violaba los derechos a la libertad de determinación, a la igualdad y al trabajo -este último incluye el derecho de toda persona a la oportunidad de ganarse la vida mediante un trabajo que él/ella elija libremente. El demandante sostenía que:

El adulto que es persuadido a vender su cuerpo en el comercio carnal ha optado por una opción no sólo constitucionalmente válida y permitida, sino acorde a su libertad de autodeterminación, pues sólo de su voluntad depende la dedicación al oficio de la prostitución, sin importar que para ello medie una inducción o persuasión ajenas, pues no está siendo constreñido, obligado o compelido para tales fines.

Se desconocen los derechos de quien, libre y voluntariamente, escoge como opción de vida la de ser intermediario de favores sexuales (actividad no prohibida), contando con la aprobación consciente del adulto que así lo acepte, al igual que la libertad de escogencia de profesión u oficio, al no permitir al proxeneta que en ejercicio de su oficio, obtenga beneficios por tal causa 
y además castiga a quien paga por los favores sexuales de la persona que se ha prostituido sin coacción alguna, en virtud de la persuasión de otra (Corte Constitucional, 2009).

La Corte mantuvo la constitucionalidad del artículo 213 declarando que:

[... como] la dignidad humana [es] un derecho constitucionalmente protegido, resulta innegable que el Estado pueda sancionar aquellas conductas que se dirigen a menoscabarla, [...] en tanto que la prostitución como actividad comporta graves consecuencias para la integridad de la dignidad de las personas, pese a la tolerancia jurídica de que es objeto, por lo que la Corte encuentra legítimo que el Estado dirija sus esfuerzos a desestimularla, a reducir sus efectos e, incluso a erradicarla, de donde resulta legítimo que el Estado sancione la conducta de quien, pese a la afectación de los derechos individuales que se deriva de la misma, se lucre de esta actividad, además que el daño social producido por la explotación de la prostitución merece ser enfrentado con medidas de punición como las sanciones penales.

Esta Corporación considera que no obstante la prostitución puede ser el resultado de una decisión libre, autónoma y voluntaria, el tipo penal acusado califica el dolo no de quien opta por prostituirse sino de quien induce, sugestiona o en general promueve la prostitución o al comercio carnal, con la intención de lucrarse o de satisfacer los deseos de una tercera persona, de donde resulta evidente que frente al riesgo de ofensa de la dignidad personal, e incluso de la autodeterminación sexual y de la propia libertad personal, el consentimiento de la víctima es una salvaguarda insuficiente, aunque el mismo no se requiera en la medida en que no es un elemento constitutivo del tipo penal acusado.

... admite que en la realidad fáctica muchas personas pueden autónomamente escoger ese modo de vida, encuentra entendible que la ley busque sancionar la actividad que pretende lucrarse de su propagación e intensificación. En suma, La Corte 
considera que el artículo 213 de la Ley 599 del 2000 no restringe desproporcionadamente los derechos fundamentales al libre desarrollo de la personalidad y a escoger profesión u oficio, como tampoco violenta el principio de lesividad, pues el fin de la norma es la protección de la dignidad humana, así como los intereses colectivos afectados por los efectos colaterales de la prostitución. (Corte Constitucional, 2009).

Sin embargo, la Corte (Corte Constitucional, 2010) un año después, en un caso en que una prostituta exigía al propietario de un burdel el reconocimiento de una remuneración adecuada, la cobertura de salud y lo pagos de jubilación, entre otros beneficios derivados de un trabajo formal, dictaminó que:

Habrá contrato de trabajo y así debe ser entendido, cuando el o la trabajadora sexual ha actuado bajo plena capacidad y voluntad, cuando no hay inducción ninguna a la prostitución, cuando las prestaciones sexuales y demás del servicio, se desarrollen bajo condiciones de dignidad y libertad para el trabajador y por supuesto cuando exista subordinación limitada por el carácter de la prestación, continuidad y pago de una remuneración previamente definida. [...] Esto en la medida en que la pretendida finalidad legítima con que se quisiera negar la licitud y exigibilidad de un contrato laboral entre persona prostituida y el propietario de prostíbulo o local donde se ejerce, está soportada en criterios que por sí mismos no hacen posible efectuar una distribución o reparto racional y equitativo de derechos, obligaciones, responsabilidades; o sea porque al desconocerlo sólo se favorecen los intereses del empresario de la prostitución, con consecuencias excesivamente gravosas para quien presta efectivamente el servicio. Pero también aparece contrario a la igualdad constitucional el desconocimiento del Derecho laboral para los y las trabajadores sexuales, porque con esta medida se restringen derechos fundamentales (al trato digno, al libre desarrollo de la personalidad y ante todo a ganarse la vida, al trabajo, a recibir una remuneración justa y equitativa) y se afecta de manera desfavorable a una minoría o grupo social tradicionalmente discriminado que se encuentra por tanto en condiciones de debilidad manifiesta. De allí el 
imperativo constitucional de reconocer sus mínimas garantías, de permitirles ser vinculadas no sólo a un sistema policivo de protección en salubridad y cuidado propio, sino también al sistema universal de seguridad social, a poder percibir prestaciones sociales, así como el ahorro para la jubilación y las cesantías.

[...] es una decisión que, aunque no resulte graciosa a los criterios de moralidad preexistentes, evita dejar en el abandono ilegítimo a las y los trabajadores sexuales como sujetos en condiciones de vulnerabilidad manifiesta, merecedores de especial protección. Pero por otro, una restricción de las garantías del trabajo, con lo que se procura evitar que el Estado, a partir de la administración de justicia, aliente el ejercicio de un oficio que, según los valores de la cultura constitucional, no es ni encomiable ni promovible.

Estas decisiones muestran a una Corte con doble cara, al estilo de $\mathrm{Jano}^{15}$. Una cara para proteger los derechos de las trabajadoras sexuales, su libre desarrollo de la personalidad, el derecho a ganarse la vida, tener y elegir un trabajo, tener una remuneración justa y equitativa. Mientras que con la otra cara defiende la constitucionalidad de disposiciones penales que combaten la promoción de la prostitución y el aprovechamiento de otros alrededor de la actividad. Esta doble cara es particularmente problemática en términos reales, pues, por un lado, los empleadores de las prostitutas tienen que promover su negocio con el fin de que sea rentable para poder así pagar los beneficios que un trabajador regular debe disfrutar, pero por el otro, la actividad de promoción es ilegal. La única explicación para esta posición es la de una Corte que cree que la prostitución es inmoral y no debe promoverse, pero que reconoce, al mismo tiempo, que en el caso extremo en que alguien termine siendo trabajador sexual sus derechos no pueden ser violados, pero, para hacer más complicadas las cosas, reconoce también que el Estado tiene el derecho y el deber jurídico de

15 Jano (en latín Janus) es, en la mitología romana, un dios que tiene dos caras mirando hacia ambos lados de su perfil. Jano es el dios de las puertas, los comienzos y los finales. 
imposibilitar la realización de esos derechos al activar la persecución penal de sus empleadores.

Lo anterior hace más compleja la situación en términos del delito de la trata de personas, ya que envía mensajes distorsionados a los funcionarios judiciales, quienes deben seguir los precedentes de la Corte. En virtud de la primera decisión (C-636 del 2009) la actividad ilegal no es la prostitución, pero sí la empresa alrededor de ella, y en virtud de la segunda (T-629 del 2010) la empresa es legal, y lo que es ilegal es no es dar derechos laborales. En la primera decisión la agencia de la prostituta es irrelevante, pero en la segunda es necesaria para poder recibir derechos laborales. Por lo tanto, la agencia del trabajador sexual es irrelevante cuando se trata de exculpar al promotor, pero funciona para obtener beneficios económicos asociados con los servicios sexuales. Esto es particularmente importante, ya que, según la Ley del Trabajo en Colombia, si el objeto del contrato es ilícito, como en el caso de la venta de drogas o la comercialización de servicios sexuales con un tercero -como en un burdel, por ejemplo-, el contrato es nulo y queda sin efectos ${ }^{16}$.

Así las cosas, la apropiación colombiana de la definición internacional de trata de personas tiene dos resultados. Por un lado, la Ley Penal colombiana está completamente ajustada a la norma internacional, e incluye más garantías cuando elimina los "medios" para todas las víctimas, no sólo las menores de edad, y cuando adiciona escenarios de tráfico, como la mendicidad y el turismo sexual. Sin embargo, este delito innovador y creativo se enfrenta a la reticencia de las autoridades judiciales. Una importante cantidad de ellas confunde la infracción con otros delitos relacionados con la explotación sexual que son parte del Código Penal. Al mismo tiempo, el hecho de que el delito de trata de personas tipifique diferentes acciones disuade a los funcionarios para iniciar el procesamiento

\footnotetext{
16 Las reglas de los contratos son de carácter general, proceden del Código Civil y el Derecho Laboral sigue la mayoría de ellas. Así pues, el artículo 1502 del Código Civil establece las condiciones de validez de los contratos: "Para que una persona se obligue a otra por un acto o declaración de la voluntad, es necesario: 1) para ser legalmente capaz; 2) Permitir el acto o declaración y su consentimiento no sufre de vicio; 3) que cae sobre un objeto lícito; 4) Tener una causa lícita la misma manera”. El artículo 1519 del Código Civil establece: "Hay un propósito ilegal en todo lo contrario a la ley pública de la nación". Es más que obvio que esto incluye la normativa penal.
} 
con el fin de simplificar su trabajo. Por último, la interpretación del Tribunal Constitucional Colombiano sobre una de las disposiciones relacionadas con la explotación sexual ha profundizado la confusión, pues confronta factores como la agencia y la legalidad de las empresas de comercio sexual con resultados contradictorios.

Hoy por hoy, diez años después del cambio de la Ley Penal en torno a la cuestión de la trata de personas, en Colombia aún no se sabe qué hacer frente al crimen de trata, cómo procesarlo de manera efectiva y poner fin a la impunidad. Esto se hace evidente por el lugar que perdió Colombia, en el 2014, en el rango de los Tier Placements Rank ${ }^{17}$ realizado por el Departamento de Estado año a año (U.S. Departmet Of State, 2014). Entre otras razones, el Departamento de Estado de los Estados Unidos sostuvo que:

Las autoridades no tratan todos los casos internos de tráfico sexual [...] como la trata de personas, lo que obstaculiza los esfuerzos para evaluar con precisión los esfuerzos del gobierno para identificar y asistir a las víctimas y para investigar y enjuiciar los casos de trata. Los gobiernos departamentales carecen de suficientes fondos, personal, o la coordinación interinstitucional para brindar servicios especializados adecuados a las víctimas de la trata.

\section{Datos sobre trata de personas, analizando lo no sexual}

El tráfico sexual en Colombia es un problema que afecta a las personas traficadas con fines de explotación sexual, que en su mayoría son mujeres y niñas, y que se enfrentan a graves violaciones de derechos humanos. Hoy en día, el trabajo de las organizaciones

17 En 2016 Colombia recuperó su lugar en el Tier. Allí fue identificado como uno de los países cuyos gobiernos cumplen plenamente los estándares mínimos de la Ley de Protección de Víctimas de la Trata (TVPA). 
no gubernamentales, la academia ${ }^{18}$ y el gobierno ${ }^{19}$ en torno al tema es mayor que nunca.

Sin embargo, el tráfico sexual no es el único delito castigado en virtud del Protocolo de Palermo o del artículo 188-A del Código Penal colombiano. Sin embargo, según el Informe Mundial sobre la Trata de Personas de la UnODC (2009, p. 9):

La forma más común de la trata de personas (79\%) es la explotación sexual. Las víctimas de la explotación sexual son predominantemente mujeres y niñas.

La segunda forma más común de la trata de personas es el trabajo forzado (18\%), aunque esto puede ser no real, pues el trabajo forzoso se detectó con menos frecuencia y se reportó menos que la trata con fines de explotación sexual.

UnODC es consciente del sesgo en estas estadísticas, no solo porque la explotación sexual es la forma más visible de la trata, sino también porque no encaja con las estadísticas de otros organismos en el ámbito internacional, como el Fondo de las Naciones Unidas. Para la Infancia de las Naciones (Unicef), la Oficina Internacional de Migraciones (OIM) y la Organización Internacional del Trabajo (оIт). Según Unicef, la "estimación de la oit de 1,2 millones de niños siendo objeto de trata cada año sigue siendo la referencia”. En el mismo sentido, la ort estima que:

... cerca de 21 millones de personas son víctimas de trabajo forzoso $^{20}-11.400 .000$ mujeres y niñas y 9,5 millones de hombres

18 Véase Polanía (2001); Lillie (2014); Steel (2006, p. 77); Fox (14 de mayo del 2012); Women's Link Worldwide (2013); Hurtado y Pereira-Villa (2014); undoc (2013); Boone (2014). 19 La Ley 985 del 2005 (además de la modificación del delito) creó el Comité Interinstitucional de Lucha contra la Trata de Personas; 18 entidades forman parte de este comité y, de acuerdo con su página web, "logra un esfuerzo conjunto para combatir y crear conciencia de todos los lados en la importancia y la magnitud del delito de la trata”. El comité cuenta con una secretaría técnica permanente para garantizar la correcta ejecución de las funciones; el Secretario Técnico es del ministro del Interior. La Secretaría Técnica y el Centro de Operaciones Anti Trata (СOAT) coordinan las entidades que conforman el Comité, así como la asistencia a las víctimas de este delito. 20 Es importante señalar que, de acuerdo con la orT "El trabajo forzoso, las formas contemporáneas de esclavitud, la servidumbre por deudas y la trata de seres humanos están estrechamente relacionadas, aunque no son idénticas en un sentido legal. La mayoría de las situaciones de esclavitud o la trata de personas se incluyen en la definición del trabajo forzoso de la oIT". Véase oit, 2017. 
y niños. Casi 19 millones de víctimas son explotadas por particulares o empresas, y más de 2 millones por los Estados o grupos rebeldes. De aquellos explotados por particulares o empresas, 4,5 millones son víctimas de la explotación sexual forzada. (ILO, s.f.).

Del mismo modo, la orm en la " 7 a Conferencia Sudamericana sobre Migraciones”, señaló que en Colombia:

\begin{abstract}
Sigue siendo difícil cuantificar la magnitud del problema y el número de víctimas afectadas, el Estado colombiano emerge como un país en el que el delito se produce con diversos fines diferentes a la explotación sexual de adultos, especialmente el trabajo infantil forzado y el reclutamiento forzado de menores de edad para los grupos armados ilegales. (Iом, 2007, p. 19)
\end{abstract}

A pesar de lo que muestran los datos disponibles, y de la preocupación y sugerencias de las organizaciones internacionales, el país ha estado trabajando en la lucha contra el tráfico sexual como la expresión más importante de la trata de personas. Esta afirmación se apoya en la práctica judicial, según el Centro de Operaciones Anti Trata (COAT), las acciones judiciales para la trata de personas, dentro y fuera de Colombia, del 2008 al 2009 y del 2011 al 2013, se representan en la tabla 1.

Está claro que la mayoría de los casos son de explotación sexual en el extranjero, a pesar de que las recomendaciones de la sociedad civil y del Departamento de Estado de los Estados Unidos se centren en cambiar el enfoque al de trata interna. La explotación sexual representa el 78,7\% de todos los casos de trata de personas en Colombia, mientras que la explotación laboral es solo del 16,6\% y la explotación en el extranjero representa el 95\% de todos los casos. Estos números son preocupantes porque no guardan coherencia con las tendencias internacionales, así como con los números nacionales en comparación con otros delitos (Abadía, 2012, p. 114). Además del extenso subregistro, el Estado no cuenta con información sistemática y datos rigurosos sobre el delito. Por ejemplo, en el 2009, el Ministerio de Asuntos Exteriores de Colombia informó sobre más víctimas externas que lo que se informa en el COAT sumando la trata interna y externa (139 de la 
Cancillería frente a 103 del COAT). Las víctimas promedio oscilan en 42 por año, según el Ministerio de Asuntos Exteriores, pero, para el Departamento de Estado de los Estados Unidos, el rango en el que oscilan es de 130. El Departamento de Estado crea y produce los datos con la información proporcionada por los organismos de diferentes ministerios y oficinas del gobierno. Para el coAT, el promedio es de 80 víctimas por año, mientras que para la UNODC (2009), que en su informe cita la Oficina del Fiscal General, es de 109 (Vargas-Trujillo, et al., p. 19). El hecho de que el gobierno no cuente con un tratamiento sistemático de los datos crea barreras importantes para la investigación adecuada del fenómeno en el país y oscurece cualquier aproximación de política pública necesaria.

\begin{tabular}{|c|c|c|c|c|c|c|c|c|c|c|c|}
\hline \multirow{2}{*}{ Fin - propósito } & \multicolumn{2}{|c|}{2008} & \multicolumn{2}{|c|}{2009} & \multicolumn{2}{|c|}{2011} & \multicolumn{2}{|c|}{2012} & \multicolumn{2}{|c|}{2013} & \multirow{2}{*}{ Total } \\
\hline & DP & FP & DP & FP & DP & FP & DP & FP & DP & FP & \\
\hline Explotación sexual & 15 & 31 & 14 & 60 & 0 & 20 & 1 & 33 & 0 & 34 & 208 \\
\hline Explotación laboral & 1 & 2 & 1 & 12 & 0 & 1 & 0 & 4 & 0 & 23 & 44 \\
\hline Matrimonio servil & 1 & 0 & 0 & 2 & 0 & 0 & 0 & 0 & 0 & 3 & 6 \\
\hline Mendicidad & 2 & 0 & 1 & 0 & 0 & 0 & 0 & 0 & 0 & 0 & 3 \\
\hline Servidumbre & 0 & 1 & 1 & 0 & 0 & 0 & 0 & 0 & 0 & 0 & 2 \\
\hline Extracción de órganos & 0 & 0 & 1 & 0 & 0 & 0 & 0 & 0 & 0 & 0 & 1 \\
\hline Subtotal & 19 & 34 & 18 & 74 & 0 & 21 & 1 & 37 & 0 & 60 & \\
\hline Total año & \multicolumn{2}{|c|}{53} & \multicolumn{2}{|c|}{92} & \multicolumn{2}{|c|}{21} & \multicolumn{2}{|c|}{38} & \multicolumn{2}{|c|}{60} & 264 \\
\hline
\end{tabular}

Fuente: elaboración propia a partir de COAT (s.f.) y

Consejo Permanente de la oea (26 de marzo del 2009).

Como la mayoría de los casos conocidos por el Estado son casos de explotación sexual, algunas de las otras modalidades del delito han pasado inadvertidas por los funcionarios judiciales y los funcionarios públicos. Esta situación ha llamado la atención de la Corte Constitucional, que, en marzo del 2013, emitió una orden directiva al gobierno para aumentar los esfuerzos de aplicación de 
la Ley contra la servidumbre doméstica ${ }^{21}$. De la misma manera, el reporte "Trata de Personas del 2014" del Departamento de Estado indica que el gobierno colombiano debía:

... aumentar los esfuerzos policivos contra la servidumbre doméstica, pero las autoridades no informaron ninguna investigación o procesamientos por esa forma de tráfico, ni por trabajo forzoso o cualquiera condena por otras formas de tráfico que no sea el reclutamiento de niños por parte de grupos armados ilegales.

[Por lo tanto], mientras que la legislación colombiana penaliza todas las formas de trata de personas, las estructuras gubernamentales y las prácticas de aplicación de la ley no reflejaron un enfoque integral. La recolección de datos se mantuvo fuerte en los esfuerzos de aplicación de la ley contra el tráfico transnacional, pero fue desigual en los esfuerzos contra el tráfico sexual interno y el trabajo forzoso. (U.S. Department of State, s.f.).

A pesar de estas recomendaciones, el vacío legal alrededor de este tema es preocupante, pues ni el Protocolo de Palermo ${ }^{22}$ ni el artículo 188-A definen la explotación laboral. Algunos académicos y operadores jurídicos han considerado que tal definición debe ajustarse a la desarrollada en 1932 por el Convenio de la oIT sobre Trabajo forzoso (C29), que establece que "el término trabajo forzoso $\mathrm{u}$ obligatorio designa todo trabajo o servicio exigido a un individuo bajo la amenaza de una pena cualquiera y para el cual dicho

21 En la Sentencia T-1078 del 2012, la Corte dijo que "como garantía de no repetición, ordena al Ministerio del Interior, de acuerdo con la ley 985 del 2005, la realización de campañas dirigidas a erradicar definitivamente de conformidad con las obligaciones internacionales del Estado colombiano, prácticas tales como la esclavitud, la servidumbre y el trabajo forzoso] que conduj[eron] a la presente decisión, con énfasis en las zonas rurales del país".

22 En los trabajos preparatorios del Protocolo, una definición, no incluida en el artículo 3, se refiere al trabajo forzado como "mano de obra o servicios obtenidos a través de la fuerza o la amenaza de la fuerza, o el uso de la coacción, o por medio de cualquier esquema o artificio para defraudar, entre ellos uno en el que el estado o condición resulta de una deuda o contrato hecho por esa persona y el valor de la mano de obra o servicios valorados, no se aplican al pago de la deuda o el cumplimiento del contrato (es decir, la servidumbre por deudas), o por cualquier medio o plan o patrón, incluyendo pero no limitado a pretextos y tergiversaciones falsas y fraudulentas, de tal manera que la persona cree razonablemente que él o ella no tiene otra alternativa que realizar el servicio". 
individuo no se ofrece voluntariamente”. Colombia firmó y ratificó el C29 y es considerado como uno de los convenios fundamentales por la Corte Constitucional. La orT desarrolló un nuevo Protocolo (2014), que hasta el momento tiene pocas ratificaciones y del que Colombia no es parte. Dicho Protocolo insiste en que:

los Miembros que han ratificado el Convenio tienen la obligación de cerciorarse de que el trabajo forzoso u obligatorio sea objeto de sanciones penales, con inclusión de sanciones impuestas por la ley que sean realmente eficaces y se apliquen estrictamente [...]

[...] el contexto y las formas del trabajo forzoso u obligatorio han cambiado y que la trata de personas con fines de trabajo forzoso u obligatorio, que puede implicar explotación sexual, suscita una creciente preocupación internacional y que su eliminación efectiva requiere acciones urgentes [...].

3. La definición de trabajo forzoso u obligatorio contenida en el Convenio se reafirma, por lo que las medidas contempladas en el presente Protocolo deberán incluir medidas específicas contra la trata de personas con fines de trabajo forzoso u obligatorio.

De la misma manera, la Corte Interamericana de Derechos Humanos (Corte IDH) -a la que Colombia está obligada por ser parte de la Convención Interamericana de Derechos Humanos-, siguiendo el C29, estableció que:

La 'amenaza de una pena' puede consistir en la presencia real y actual de una amenaza, que puede asumir diferentes formas y grados, de los cuales el más extremo son los que implican la coerción, la violencia física, el aislamiento o confinamiento, o la amenaza de matar a la víctima o sus familiares [...].

La "falta de voluntad para llevar a cabo la obra o servicio" consiste en la ausencia de consentimiento o de libre elección cuando la situación del trabajo forzoso comienza o continúa. Esto puede ocurrir por diferentes razones, como la privación ilegal de la libertad, el engaño o la coacción psicológica (Corte Interamericana de Derechos Humanos, 2006). 
Por lo tanto, la Corte IDH reconoció que, cuando estas circunstancias se encuentran, el Estado está en violación del artículo 6 de la Convención Interamericana de Derechos Humanos.

En consecuencia, para Colombia se refuerzan los estándares internacionales en materia de trabajo decente y las normas internacionales de trata de personas. Por esta razón el Estado podría encontrarse en violación de la Convención de las Naciones Unidas contra la Delincuencia Organizada Transnacional, el Protocolo para prevenir, reprimir y sancionar la trata de personas, especialmente mujeres y niños, el Convenio orT contra el trabajo forzoso y la Convención Interamericana de Derechos Humanos, al no tomar las medidas adecuadas contra el trabajo forzoso.

\section{El esclavo invisible}

Las situaciones de trata laboral pueden ser tan horribles como las de tráfico sexual. El siguiente es un caso paradigmático (Corte Constitucional, 2012) que describe la situación deplorable de algunas personas en el país:

[...] alrededor de la edad de seis Amalia, fue dada en adopción por su madre a la familia Beltrán Sánchez en una pequeña ciudad; donde Amalia "pagaría su crianza ${ }^{23 "}$ mediante la realización de tareas domésticas. Ella fue trasladada a Bogotá, donde fue objeto de explotación ${ }^{24} \mathrm{y}$ abusos físicos y psicológicos ${ }^{25}$.

23 Amalia nunca fue enviada a la escuela o a algún centro de educación formal. Ella aprendió a leer con los niños a su cuidado, y fue inscrita en una institución educativa solo en una oportunidad. Amalia también informa haber sido castigada por aprender a leer y escribir.

24 Ella realizaba tareas domésticas como cocinar, bañar los niños pequeños, limpiar la casa y ayudar a cuidar a los hijos de los acusados. De acuerdo con un hijo de los acusados "se entendía por esas cosas, como ella dio todo su vestuario y todo, nunca formalizó una forma de pago, en el mismo documento de adopción de acuerdo en que mi madre se hará cargo de su educación y formación, y se considera que no está obligado a pagar nada porque la educación, [...] que se considera a ser compensados por la ayuda, ésta se pagará con el trabajo de casa".

25 Fue sometida a diversos tipos de abuso. Por ejemplo, los testimonios tanto del demandante como de los demandados coinciden en que, cuando niña a Amalia se le dijo en repetidas ocasiones que su madre era una prostituta, ella le entrego al Sr. Sánchez para que supuestamente, tuviera una mejor calidad de vida. Amalia dice que ese comentario le causó muchos conflictos internos. Además, fue trasladada a la piscina porque estaba orinando dentro de la casa, se le golpeaba con tacones y era objeto de diferentes tipos de insultos. 
También fue "prestada" a otros miembros de la familia fuera del hogar para servir a ellos. La jornada de trabajo de Amalia, comenzaba temprano en la mañana - para preparar el desayuno para los niños de los acusados y les ayudaba a organizarse para ir al colegio- y terminaba en la tarde, después de preparar la comida y limpiar la cocina. Dormía en la habitación de servicio, lo que confirma el estatus que tenía en la casa de la familia Sánchez Beltrán. Ella nunca tuvo ningún tipo de compensación; en opinión de la demandada, fue suficiente darle alimentos, vivienda y ropa. Por otra parte, Amalia relata que no se le permitía tener dinero.

Después de 10 años se las arregló para huir de la casa de la familia Beltrán Sánchez, con la ayuda de una vecina y un conductor. Afirma que después de huir se enfrentó a un mundo desconocido, indocumentada y sin identidad. Ella ha tratado de reconstruir su pasado, pero ha sido imposible ${ }^{26}$.

En respuesta a la demanda, la parte demandada afirma que todos los hechos son falsos:

Y Ema (como llaman a Amalia) vivía con su madre y luego se acordó que sería trasladada a su casa, donde fue presentada a sus hijos como su hermana adoptiva. En este sentido, la chica tenía un tratamiento 'sustancialmente similar', como el recibido por los otros seis hijos biológicos, con quien vivió fraternalmente.

[...] Como era costumbre en la época, ella colaboró en las tareas domésticas y “(...) en la medida de sus posibilidades como una niña pequeña se le aplicaban sanciones o medidas correctivas también típicos de la época por sus travesuras, pero su nunca infringió tratos inhumanos o degradantes como a los que se pretende dar cabida en el caso.

26 Amalia no podía disponer de su tiempo y no podía salir de la casa de la familia Beltrán Sánchez porque no se le permitía y, además, porque era una niña sin educación que no conocía la ciudad y no tenía dinero. Durante el tiempo que pasó en la casa de la familia Beltrán Sánchez, Amalia no tuvo ningún documento de identidad. 
Para resolver esta situación, la Corte estableció que:

El artículo $17^{[27]}$ debe interpretarse de conformidad con el derecho internacional de los derechos humanos vinculantes para Colombia, como la Convención sobre la Esclavitud de 1926, el Convenio sobre el trabajo forzoso de la oit de 1930, el artículo 4 de los Derechos Humanos Declaración Universal de 1948, la Convención Suplementaria sobre la Abolición de la Esclavitud, la trata de esclavos y las instituciones y prácticas análogas a la esclavitud, de 1956, el Convenio de la orT sobre la abolición del trabajo forzoso de 1957, el artículo 8 del Pacto Internacional de Derechos Civiles y Políticos de 1966, el artículo 6 de la Convención Americana sobre Derechos Humanos de 1969, el Protocolo para Prevenir, Reprimir y Sancionar la Trata de Personas, especialmente Mujeres y Niños -Protocolo de Palermodel 2000, entre otros.

La Corte señala que en este caso se cumplen los requisitos establecidos por el derecho internacional para declarar que los acusados sometieron a Amalia a trabajos forzados, trata de personas, e incluso a una forma de esclavitud. De acuerdo con el artículo 2 del C29, sobre el trabajo forzoso, este fenómeno se produce cuando se cumplen dos condiciones: (i) la realización de trabajos o la prestación de un servicio bajo la amenaza de una pena cualquiera $u$ otra amenaza comparable, y (ii) la falta de la voluntad de la persona que realiza el trabajo o servicio; esto es, cuando el individuo no se ofrece voluntariamente.

En este caso, valga repetirlo, los hechos establecidos muestran que tales condiciones se cumplen. Ella estaba obligada a desarrollar el trabajo doméstico en jornadas extenuantes de trabajo en la casa de la familia Sánchez Beltrán, bajo amenazas de violencia física y

27 El artículo 17 de la Constitución establece que "la esclavitud está prohibida, [así como] la servidumbre y la trata de seres humanos en todas sus formas". Esta disposición está estrechamente relacionada con el artículo 1 de la Constitución. Uno de los fundamentos del Estado de derecho en Colombia, enunciado en ese artículo, es el respeto a la dignidad humana. El artículo 12 prohíbe la tortura y los tratos crueles, inhumanos o degradantes; el artículo 16 garantiza el derecho al libre desarrollo de la personalidad; y el Artículo 28 reconoce el derecho a la libertad; entre otros. 
atropellos psicológicos. La situación de amenazas se agrava por su corta edad, así como por su impotencia por falta de apoyo familiar. Estas situaciones fueron más que suficientes para generar un temor mayor contra sus tenedores. Por otra parte, Amalia nunca se ofreció voluntariamente para hacer el trabajo; de hecho, dada su corta edad, la falta de familia y de educación, no tenía otra opción. Es más, tan pronto obtuvo un mayor grado de autonomía, es decir, a sus 15 años, decidió huir de la casa de los acusados, lo cual es evidencia adicional de la falta de voluntariedad. Los demandados calificaron su salida como un escape, lo que demuestra que Amalia estaba bajo su subordinación.

A la luz de la definición de trata de personas del Protocolo de Palermo - para hablar de este caso no como un delito, sino como una violación de los derechos humanos, dada la prescripción de la acción penal-, en este caso ocurrió lo siguiente: (i) se trasladó a una persona, (ii) se tomó ventaja de su vulnerabilidad, (iii) con fines de explotación. De hecho, cuando Amalia era una niña indefensa y vulnerable, el señor Sánchez se la llevó a Bogotá con el fin de que ella llevara a cabo el trabajo doméstico no remunerado, primero en la casa de su madre, y luego en su propia casa. Aunque la Sra. Beltrán y el Sr. Sánchez dijeron recibir la niña "por razones humanitarias", lo cierto es que se aprovecharon de su vulnerabilidad al sacarla de su ciudad natal y obligarla a hacer las tareas domésticas. Nunca hubo una verdadera intención humanitaria porque la niña no fue educada en el sistema educativo formal, fue sometida a abusos, largas horas de trabajo y nunca recibió pago alguno. De hecho, el documento "contrato de adopción" y las declaraciones de los acusados muestran que esta relación nunca fue pensada para remunerar el trabajo de Amalia. Para ellos era suficiente abastecer la vivienda, y darle ropa y alimentos a Amalia.

Incluso se podría hablar de una forma de esclavitud, en los términos en los que la Convención Suplementaria sobre la Abolición de la Esclavitud, la Trata de Esclavos y las Instituciones y Prácticas Análogas a la Esclavitud de 1956 indica. Según esta, la esclavitud es toda practica en que “(...) un niño o un joven menor de dieciocho años es entregado por sus padres, o uno de ellos, o por su tutor, a otra persona, ya sea remunerado o no, con el propósito de explotar a la persona o el trabajo del niño o del joven”. En este caso, la madre de Amalia se la entregó al Sr. Sánchez con el fin de explotarla, 
porque (i) ni siquiera existió remuneración, (ii) la niña fue puesta a trabajar jornadas que claramente superaban sus capacidades -hay que recordar que ella no había llegado a la edad legal requerida para cualquier persona menor de 18 años para empezar a trabajar-. Adicionalmente, otros elementos coinciden en la definición de esclavitud de la Convención de 1926: los acusados ejercieron un poder que les permitió señalar dónde iba Amalia a ofrecer su servicio, y que hizo imposible para ella disponer de su tiempo e incluso de su cuerpo.

Así pues, la Corte mantiene una definición progresista de los efectos de la ley internacional en la comprensión de los derechos humanos en Colombia. El uso del Protocolo de Palermo, no como una herramienta para la persecución penal, sino como un conjunto útil de normas sobre derechos humanos, dan cuenta de ello. La Corte insiste en una comprensión completa y coherente de las disposiciones internacionales que pueden recomponer los derechos de las víctimas de la trata de personas.

Tal descripción de hechos se puede reproducir en diferentes momentos y zonas del país. Hacer visible la condición de esclavitud doméstica es una necesidad para lograr el enfoque del gobierno en modalidades de la trata de personas más allá del tráfico sexual, en el interior de sus fronteras y dentro de los hogares de las familias colombianas.

Como se vio, los datos muestran un importante número de trata de personas con fines de explotación sexual. Pero hoy por hoy existe la necesidad de que el Estado emprenda el trabajo de informar a la gente que sus condiciones de vida pueden considerarse como condiciones de trata de personas. Que hacer trabajar a empleados domésticos durante 15 horas al día es trabajo forzoso y no una bendición, que no pagar por el trabajo doméstico es ilegal, y que dar comida, ropa y refugio no es una licencia para la deshumanización del trabajador doméstico. De acuerdo con un informe de la oit (ILO, 2013), en el mundo, 52,6 millones de personas son trabajadores domésticos. De estos, $80 \%$ son mujeres, y solo 5,3 millones del total están cubiertos por la legislación laboral en el mismo nivel que los demás trabajadores. Así que todavía 
hay trabajo que los Estados pueden llevar a cabo para prevenir situaciones de explotación, incluso en el plano legislativo ${ }^{28}$.

\section{Aceptación cultural}

La situación es tan escandalosa como parece. La trata de personas es una práctica extendida en las ciudades de Colombia: las madres dan a sus niñas a familias de clase media o alta a cambio de que sean educadas, en su parecer, para darles una vida mejor, y como recompensa estas familias tienen cubiertas las labores del hogar de una forma gratuita durante al menos diez años.

La descripción de la historia de Amalia, y la respuesta de los demandados, muestran un problema crítico en la sociedad colombiana. Tomar niñas del campo y moverlas a las ciudades con el fin de "ayudar" con las tareas domésticas a cambio de alojamiento y comida es ilegal. Sin embargo, debido a la estrecha relación que algunas familias tienen con los trabajadores domésticos, esta "ayuda" no es vista como "trabajo", sino como un acto de caridad. Las familias saben que quieren el trabajo de esas chicas, pero no se ven a sí mismas como explotadoras. Se auto identifican, más bien, como ayudantes, como modelos a seguir para ellas, modelos para hacerlas soñar en grande -sacarlas de su pequeño pueblo es parte de ese sueño que pueden lograr cuando tengan 18 años-. Una gran cantidad de estas niñas regresa a sus lugares de origen, tiene hijos y reproduce el sistema mediante el envío de sus hijas a las mismas familias en las que ellas solían trabajar. Esto aumenta aún más la cercanía con la gente para la que trabajan, difuminando aún más la relación laboral.

Como expone un funcionario de UnODC: "Muchos de los casos de trata de personas que se producen en Colombia son el resultado de una aceptación por la comunidad de tal comportamiento, argumentando que siempre ha sido así y es costumbre" (Henao-Trip, 2008). El enfoque del Estado en la persecución de la trata sexual,

28 En Colombia, la Corte Constitucional, en las Decisiones C-310 del 2007 y T-387 del 2011, ha adoptado la teoría de que los trabajadores domésticos se encuentran en una situación de vulnerabilidad: su actividad tiene tradicionalmente poca importancia jurídica, económica y social; en ellos persiste un efecto de invisibilidad que los hace aún más vulnerables. 
como la forma de trata de personas principal que ocurre en el país, ayuda a esta aceptación cultural y perpetúa la invisibilidad de los trabajadores domésticos explotados.

Como muestra, María Roa-Borja, líder de la Unión Nacional de Trabajadores Domésticos que participó en abril del 2014 en el panel "La mujer y el trabajo para construir la paz", en "Colombia: Construcción de la Paz", en la Universidad de Harvard (Borja-Roa, M. 2015), afirma:

Muchos empleadores dicen que no saben la ley, o camuflar su falta de cumplimiento con el pretexto de compensar a los trabajadores con los intangibles, como la amabilidad y el buen trato, o bienes y servicios sobrevaluados para ellos como refugio o alimento.

Ahora sabemos que no necesitamos pedir la caridad de los empleadores, en algunas partes les decimos patrón, y aunque apreciamos la ropa de segunda mano que nos dan, sabemos que esto no es negociable respecto nuestro salario. [...] Nosotros no necesitamos ser considerados parte de la familia de los empleadores, porque ya tenemos una familia, y aunque sentimos el amor, por ejemplo, por los niños que cuidamos, sabemos que tarde o temprano nos vamos a ir, vamos a dejar de verlos, o se convertirán en nuestros jefes, y la cosa va a cambiar radicalmente. Hemos empezado a hablar de derechos. Los derechos de estudiar en estas universidades.

María expresa la forma en que se debe entender la relación con las familias: como una relación estrictamente laboral. Así es como debe ser, no solo en virtud de las normas legales actuales, sino también como una forma cultural que permita detener la trata de personas con fines de trabajo forzoso al interior de los hogares. Este trabajo no se respeta con el amor, la caridad o ayuda, sino con los salarios, la jornada laboral justa y la privacidad, factores esenciales para humanizar la relación que los colombianos tienen con sus proveedores de servicios domésticos. 


\section{Conclusión}

Colombia ha recorrido un largo camino en la construcción de un sistema jurídico garante de los derechos humanos. Sin embargo, el Estado debe prestar atención a las consecuencias inintencionadas de su política criminal, publicidad en turismo y lo que se permite y acepta culturalmente. El análisis de los datos es un primer paso en la comprensión de violaciones masivas de los derechos humanos. La sociedad civil y la academia tienen un papel en la garantía de los derechos humanos. El empoderamiento de personas como María Roa es útil para el desarrollo de una nueva actitud hacia los trabajadores invisibles, incluso más si estos trabajadores son explotados o son víctimas de trata de personas.

\section{Referencias}

Abadía, M. (2012). Usos y abusos del sistema penal. Su uso como forma de emancipación femenina: un estudio de caso del delito de trata de personas en Colombia. Revista de Estudios Sociales, 42, 104-117. Recuperado de https://revistas.uniandes.edu.co/doi/pdf/10.7440/ res42.2012.10

Anderson, S. (2002). Prostitution and Sexual Autonomy: Making Sense of the Prohibition of Prostitution. Ethics, 112(4), 748-780.

Asamblea General de las Naciones Unidas. (2000). Protocolo para prevenir, reprimir y sancionar la trata de personas, especialmente mujeres y niños, que complementa la Convención de las Naciones Unidas contra la Delincuencia Organizada Transnacional, Complementando la Convención de Naciones Unidas contra el Crimen Trasnacional Organizado. Recuperado de http://www.refworld.org/ docid $/ 4720706 \mathrm{c} 0 . \mathrm{html}$

Boone, R. (2014). Sex Tourism: Human Trafficking in Colombia. Human Rights Brief, Center for Human Rights and Humanitarian Law. Recuperado de http://hrbrief.org/2014/02/sex-tourism-humantrafficking-in-colombia/

Borja-Roa, M. (24 de abril del 2015). Conferencia Colombia construye paz. Ponencia presentada en la Universidad de Harvard. Recuperado de http://www.bienhumano.org/images/actualidad/Conferencia_Maria_ Roa_Harvard.pdf

Bromberg, S. (1997). Feminist Issues in Prostitution. Recuperado de http:// www.feministissues.com/ 
Burns, L. (21 de junio, s.a.). 10 Of the Most Popular Destinations for Sex Tourism. [Entrada de blog]. Recuperado de http://www.therichest. com/rich-list/most-popular/10-of-the-most-popular-destinations-forsex-tourism/

Carr, B., Milgram, A., Kim, K., y Warnath, S. (2014). Human Trafficking Law and Policy. New York: LexisNexis.

Centro de Operaciones Anti Trata [COAT]. Trata de personas. Recuperado de http://tratadepersonas.mininterior.gov.co/trata-de-personas/ estadisticas)

Consejo Permanente de la oeA. (26 de marzo del 2009). Logros y avances del gobierno de Colombia en materia de lucha contra la trata de personas. Recuperado de http://scm.oas.org/doc_public/SPANISH/ HIST_09/RA00096T04.doc

Corte Constitucional de Colombia, Sentencia del 16 septiembre de 2009. Magistrado Ponente Mauricio González Cuervo. (Sentencia C-636 de 2009)

Corte Constitucional de Colombia. (2010). Sentencia del 13 de agosto del 2010. Magistrado Ponente Juan Carlos Henao Pérez. (Sentencia T-629 del 2010)

Corte Constitucional de Colombia. (2011). Sentencia del 11 de mayo del 2011. Magistrado Ponente Luís Ernesto Vargas Silva. (Sentencia C-371 del 2011)

Corte Constitucional de Colombia. (2012). Sentencia del 12 de diciembre 2012. Magistrado Ponente Jorge Ignacio Pretelt Chaljub. (Sentencia T-1078 de 2012)

Corte Interamericana de Derechos Humanos (2006), Sentencia de 1 de julio del 2006. Masacres de Ituango v. Colombia, párr. 159-165, 2006

Daily Mail Reporter. (13 de mayo del 2013). The Sofia Vergara effect? Colombian women are ranked sexiest in the world, while Brits top the poll for men. Daily Mail Online. Recuperado de http://www.dailymail. co.uk/femail/article-2323973/The-Sofia-Vergara-effect-Colombianwomen-ranked-sexiest-world-Brits-poll-men.html\#ixzz3ZV6oJuNv

Editorial. (13 de noviembre del 2017). Turismo sexual en auge: El primer paso para enfrentar este flagelo es reconocer su existencia y las dimensiones alcanzadas. El Tiempo. Recuperado de http://www. eltiempo.com/opinion/editorial/turismo-sexual-en-auge-en-ciudadesde-colombia-150954

Fox, E. (14 de mayo del 2012). Case Highlights Importance of Colombia To Global Sex Trade. Insight Crime in the Americas. Recuperado de http:// www.insightcrime.org/news-analysis/case-highlights-importance-ofcolombia-to-global-sex-trade

Henao-Trip, M. I. (2008). Lucha contra la trata de personas: Desafío para Colombia en el siglo xxı. Estudios Criminológicos, Policía Nacional de 
Colombia. Recuperado de http://www.policia.gov.co/imagenes_ponal/ dijin/revista_criminalidad/vol50_1/15lucha.pdf

Hurtado, M., y Pereira-Villa, C. (2012). Dinámica del comercio ilícito de personas: el caso de Colombia-Oriente Asiático. Colombia Internacional, 76, 167-194. Recuperado de http://www.scielo.org.co/pdf/rci/n76/ n76a07.pdf

International Labour Organization [ILo]. (s.f.). Human trafficking and slavery. Recuperado de http://www.ilo.org/global/topics/forcedlabour/lang--en/index.htm

International Labour Organization [ILo]. (2013). Domestic Workers Across the World: Global and Regional Statistics and the Extent of Legal Protection. Suiza: International Labour Office. Recuperado de http://www. ilo.org/wcmsp5/groups/public/---dgreports/---dcomm/---publ/ documents/publication/wcms_173363.pdf

International Labour Organization [ILO]. (2017). Estimaciones mundiales sobre la esclavitud moderna: trabajo forzoso y matrimonio forzoso. Ginebra: International Labour Office. Recuperado de http://www.ilo.org/ wcmsp5/groups/public/@ed_norm/@ipec/documents/publication/ wcms_596485.pdf

Landau, S. (8 de abril del 2008). A Case for the Legalization of Prostitution: A Critical Analysis of Liberal versus Radical-Feminist Views on Sex Work. Recuperado de https://archive.is/6Y6Q\#selection-49.0-61.1

Lillie, M. (2014). The Sex Trafficking of Colombian Women, Human Trafficking Search. Recuperado de http://humantraffickingsearch. net/wp/the-sex-trafficking-of-colombian-women/

Ley 599 del 2000, Código Penal, Diario Oficial 44097 de julio 24 del 2000.

Ley 747 del 2002, reformas y adiciones al Código Penal (Ley 599 de 2000), se crea el tipo penal de trata de personas y se dictan otras disposiciones, Diario Oficial 44.872, de julio 19 del 2002

Ley 890 del 2004, modifica y adiciona el Código Penal, Diario Oficial No. 45.602, de julio 7 del 2004

Ley 985 del 2005, medidas contra la trata de personas y normas para la atención y protección de las víctimas de la misma, Diario Oficial No. 46.015 de agosto 29 del 2005.

Lucas, A. M. (1995). Race, Class, Gender and Deviancy: The criminalization of prostitution. Berkeley Women's Law Journal, 10(1), 47-60.

Luna de Aliaga, B., Mateus, A., Varón, A., y Vanegas, M. (15 de diciembre del 2009). Aspectos jurídicos del delito de trata de personas en Colombia. Recuperado de http://www.unodc.org/documents/ colombia/2013/septiembre/Investigacion_U_Rosario.pdf

Moreno, C. (13 de mayo del 2013). Colombian Women Voted Sexiest In The World, Miss Travel Poll Finds. The Huffington Post. Recuperado de http://www.huffingtonpost.com/2013/05/13/sexiest-women-in-theworld_n_3255473.html 
Montoya, V. (2012). ¿Trabajadora sexual o "víctima perfecta”? Límites en el acceso a la justicia. Prisma Jurídico, 11(1), 143-161. Recuperado de http://www.redalyc.org/pdf/934/93426128008.pdf

Oficina de Naciones Unidas Contra la Droga y el Delito [unodc]. (2009). Global Report on Trafficking in Persons. Recuperado de http://www. unodc.org/documents/human-trafficking/Executive_summary_ english.pdf

Oficina de Naciones Unidas Contra la Droga y el Delito [unOdc]. (2013). Estudio Exploratorio Descriptivo de la dinámica delictiva del tráfico de estupefacientes, la trata de personas y la explotación sexual comercial asociada a viajes y turismo en el municipio de Medellín, Colombia. Recuperado de http://www.unodc.org/documents/ colombia/2013/Noviembre/UNODC_Medellin.pdf

O'Neill, M. (2001). Prostitution and Feminism. Cambridge: Polity Press.

Organización Internacional para las Migraciones [IOM]. (2007). Séptima Conferencia Sudamericana sobre migraciones: La trata de personas en la región sudamericana. Compilación de actividades realizadas por oIm y sus contrapartes. Recuperado de http://www.acnur.org/ t3/fileadmin/scripts/doc.php?file=t3/fileadmin/Documentos/ BDL/2007/5575

Polanía, F. (2001). Japan, the Mecca for Trafficking In Colombian Women. Recuperado de http://www.childtrafficking.com/Docs/polania_ molina_2001__japan_.pdf

Pound, R. (1927). Law and Social Change. Indiana Law Journal, 3(3), 183195. Recuperado de http://www.repository.law.indiana.edu/ilj/vol3/ iss $3 / 1$

Presidencia de la República. (s.f.). Así es Colombia 2005. Recuperado de http://wsp.presidencia.gov.co/asiescolombia/colombia.html

Procolombia. (s.f.). Exportaciones Turismo Inversión Marca País. Recuperado de http://www.colombia.travel/es

Ruiz-Navarro, C. (11 de septiembre del 2013). La feria de las flores. El Espectador. Recuperado de http://www.elespectador.com/opinion/ feria-de-flores-columna-445803

Steel, A. (2006). Insecurity and Opportunity in Colombia: Linking Civil War and Human Trafficking. K. D. Beeks, y D. Amir, Trafficking $\mathcal{E}$ the Global Sex Industry (pp. 77). Oxford: Lexington Books.

Suarez Buelvas, R. (4 de febrero del 2008). Colombia Is Passion - (Inglés) [Archivo de video]. Recuperado de: https://www.youtube.com/ watch?v=Hn4hMEOpF8o\&list=RDsRTU89rRpCI\&index=22

U.S. Department of State. (s.f.). Trafficking in Persons Report 2014. Recuperado de http://www.state.gov/j/tip/rls/tiprpt/2014/index.htm Von Hirsh, A. (1993). Censure and Sanctions. Oxford: Clarendon Press. Women's Link Worldwide. (2013). Colombia must focus more on tackling internal human trafficking-report. Recuperado de http:// 
www.womenslinkworldwide.org/wlw/new.php? modo=detalle_ prensa\&dc $=437 \&$ lang $=$ en

World Travel y Tourism Council. (2017). Travel E Tourism: Economic Impact 2017, Colombia. Recuperado de https://www.wttc.org/-/media/files/ reports/economic-impact-research/countries-2017/colombia2017.pdf Vargas-Trujillo, E., et al. (2011). Trata de personas en Colombia: una aproximación a la magnitud y comprensión del problema. огм y Universidad de los Andes. Recuperado de http://www.oim.org.co/ publicaciones-oim/trata-de-personas/1522-trata-de-personas-encolombia-una-aproximacion-a-la-magnitud-y-comprension-delproblema.html 